\title{
Penerapan Metode Otsu dalam Melakukan Segmentasi Citra pada Citra Naskah Arab
}

Mhd. Furqan, Sriani, Indah Eka Yulia Sari

Universitas Islam Negeri Sumatera Utara Medan, Indonesia

\section{Informasi Artikel}

Article history:

Received, 25 April 2020

Revised, 2 May 2020

Accepted, 2 July 2020

\section{Kata Kunci:}

Citra

Naskah Arab

Metode Otsu

Segmentasi Citra

Intensitas Gambar

\section{Keywords:}

Image

Arabic script

Otsu Method

Image Segmentation

Image Intensity

\begin{abstract}
ABSTRAK
Sejarah berdirinya agama Islam di provinsi Sumatera Utara memiliki kisah tersendiri dan telah di tuliskan di dalam naskah arab. Bentuk dari naskah arab bisa rusak karena disimpan begitu lama, dari kerusakan tersebut informasi di dalam naskah menjadi berkurang. Agar dapat mencegah berkurangnya informasi di dalam naskah perlu digitalisasi dengan melakukan proses segmentasi. Segmentasi merupakan metode yang mempunyai tujuan agar dapat memisahkan sebuah gambar menjadi beberapa daerah dan tiap-tiap daerahnya mempunyai atribut yang sama. Untuk dapat melaksanakan proses tersebut penulis mengimplementasikan metode Otsu, dari citra yang telah dimasukkan nilai ambang dapat ditentukan secara otomatis. Metode Otsu bekerja dengan teknik pencarian nilai penyebaran intensitas gambar yang dimasukkan, nilai bobotnya dicari berdasarkan kedua kelasnya, perhitungan rerata terhadap dua kelas, total dari nilai rerata, dan mecari nilai Beetwen Class Variance. Pengimplementasian terhadap sistem yang telah dibuat disimpulkan bahwa tulisan yang terdapat pada naskah arab dapat dilihat dengan jelas jika dibandingkan dengan citra naskah arab sebelum melakukan proses segmentasi.
\end{abstract}

\begin{abstract}
The history of the establishment of Islam in the province of North Sumatra has its own story and has been written in Arabic script. The form of Arabic script can be damaged because it is stored for so long, from the damage the information in the script is reduced. In order to prevent the lack of information in the script it is necessary to digitize by doing the segmentation process. Segmentation is a method that aims to separate an image into several regions and each region has the same attributes. To be able to carry out the process the writer implements the Otsu method, from the image that has been entered the threshold value can be determined automatically. The Otsu method works with the search technique for inserting the intensity value of the inserted image, the weight value is sought based on the two classes, the average calculation of the two classes, the total of the mean values, and looking for the Beetwen Class Variance value. Implementation of the system that has been made concluded that the writing contained in the Arabic script can be seen clearly when compared with the Arabic script image before doing the segmentation process.
\end{abstract}

This is an open access article under the CC BY-SA license.

\section{Corresponding Author:}

Indah Eka Yulia Sari,

Program Studi Ilmu Komputer,

Universitas Islam Negeri Sumatera Utara.

Email: indahekayuliasari@uinsu.ac.id 


\section{PENDAHULUAN}

Informasi mengenai sejarah berdirinya agama Islam di provinsi Sumatera Utara begitu penting bagi para penerus bangsa ini. Segala informasi tersebut telah tertuang pada naskah arab, sehingga pada penelitian ini penulis menjadikan naskah arab sebagai objek. Naskah merupakan sebuah tulisan yang mempunyai tujuan untuk mengetahui kisah kehidupan sosial masyarakat dimasa lalu [1]. Naskah arab adalah sebuah kejadian yang pernah terjadi di masa lampau yang diimplementasikan dalam bentuk tulisan (naskah) yang bersifat kekal dan memiliki jumlah yang banyak [2]. Umumnya naskah arab ditulis menggunakan tangan di atas kertas oleh manusia. Bentuk dari naskah arab bisa rusak karena disimpan begitu lama, penyebab lain yang dapat merusak bentuk fisik dari naskah arab salah satunya adalah tanah longsor, banjir, dan tsunami. Dari kerusakan tersebut informasi yang ada di dalam naskah menjadi berkurang, pada dasarnya sebuah informasi yang menggunakan tulisan berbahasa arab jika salah membaca satu huruf saja maka maknanya juga akan salah. Dengan cara digitalisasi atau mengubah format naskah arab menjadi citra digital dapat memperindah kembali bentuk dari naskah arab. Manusia merupakan makhluk visual dengan mengandalkan mata untuk mengetahui dunia sekelilingnya. Mata manusia mampu menggambarkan objek untuk mendapatkan sebuah informasi, cahaya dan bayangan dapat mempengaruhi sebuah objek dalam dunia nyata [3] . Dalam jurnal lain objek yang direpresentasikan oleh sebuah citra memiliki banyak informasi dan manfaat dari penyebaran intensitas cahaya yang ada pada bidang dua dimensi merupakan defenisi sebuah citra [4]. Agar citra analog bisa diolah di dalam sebuah komputer olah citra tersebut dengan menjadikannya citra digital. Pengolahan Citra digital merupakan pemrosesan sebuah citra menggunakan komputer agar citra tersebut mudah diinterpretasikan oleh manusia ataupun mesin [5].Citra digital merupakan citra yang dapat diproses langsung di dalam komputer, isi dari citra digital adalah nilai komplek direpresentasikan menggunakan deretan bit tertentu [6]. Naskah dengan bentuk digital sangat menarik perhatian generasi muda untuk membacanya dan menambah pengetahuan mengenai isi yang terkandung di dalam naskah tersebut. Agar dapat menghindari terjadinya pengurangan informasi pada naskah arab yang disebabkan oleh berbagai macam hal yang telah disebutkan sebelumnya penulis melakukan proses segmentasi. Segmentasi merupakan metode yang mempunyai tujuan agar dapat memisahkan sebuah gambar menjadi beberapa daerah dan tiap-tiap daerahnya mempunyai atribut yang sama [7]. Untuk dapat melaksanakan teknik tersebut penulis mengimplementasikan metode Otsu, dari citra yang telah dimasukkan nilai ambang dapat ditentukan secara otomatis dengan menggunakan Metode Otsu []. Dengan memaksimalkan nilai dari Between Class Variance proses komputasi menjadi lebih cepat dalam mengimplementasikan metode Otsu [9]].

\section{METODE PENELITIAN}

Untuk mengidentifikasi permasalahan yang telah ditemui digunakanlah metode penelitian, setelah itu menganalisa permasalahan dari penelitian tersebut dan akhirnya akan mencari solusi untuk menyelesikan masalah tersebut. Di dalam penelitian ini dibutuhkan sebuah cara untuk menyelesaikan masalah dalam melakukan proses segmentasi naskah arab dengan mengimplementasikan metode Otsu sehingga informasi yang ada pada naskah tersebut tidak berkurang.

\subsection{Kerangka Kerja}

Agar penelitian bisa dijalankan dengan lancar ada langkah-langkah yang wajib dilalui, langkah-langkah tersebut merupakan urutan dari sebuah kerangka kerja yang juga sering disebut sebagai metodologi penelitian. Gambar dibawah ini merupakan kerangka kerja yang wajib ditempuh:

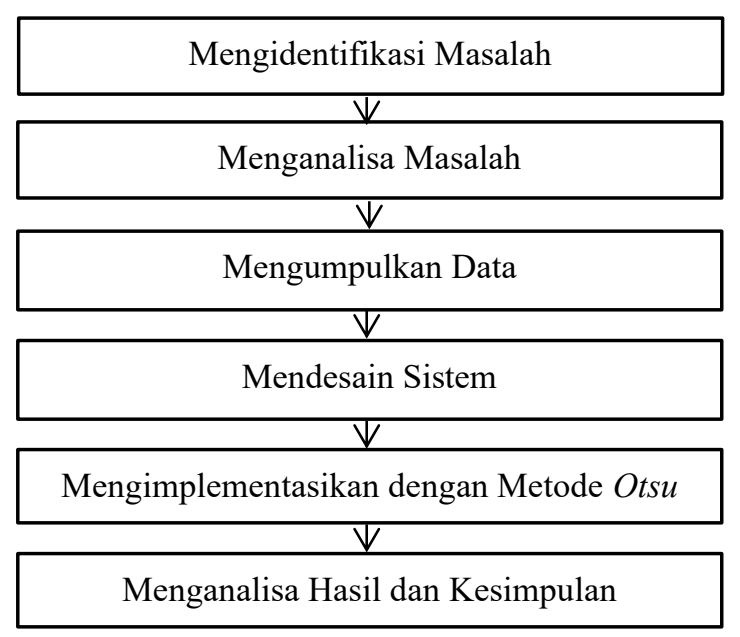

Gambar 1. Kerangka Kerja 
Dari analisis yang telah dilalui penulis juga telah membuat sebuah perancangan sistem yang berguna untuk memudahkan seorang user dalam menggunakan aplikasi segmentasi citra naskah arab dalam mengimplementasikan metode Otsu. Perancangan tersebut terdiri dari perancangan flowchart sistem dan metode yang digunakan, serta form pengimplementasian metode $O t s u$ dalam menjalankan proses segmentasi citra naskah arab.

Dalam komputasi alat yang mampu menunjukkan langkah-langkah yang harus ditempuh dalam mengatasi sebuah masalah dan menerapakannya ke dalam simbol-simbol khusus di sebut sebagai Flowchart [10]. Dalam referensi lain flowchart adalah sebuah diagram yang dapat menjelaskan dengan detail proses sebuah program [11].

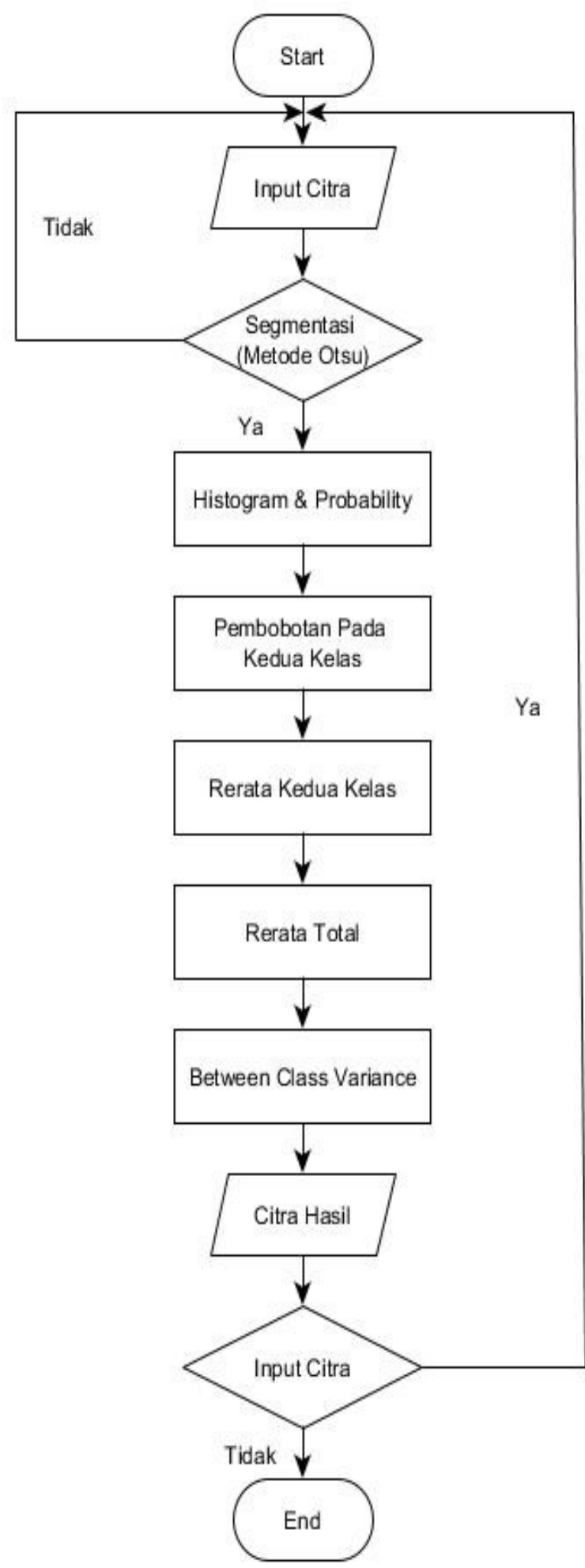

Gambar 2. Flowchart metode Otsu 
Gambar 2 adalah flowchart metode Otsu yang merupakan langkah-langkah yang harus ditempuh dalam menjalankan proses penerapan metode Otsu dalam melakukan segmentasi citra pada citra naskah arab.

Langkah flowchart metode Otsu adalah Start, selanjutnya Input Citra Grayscale. Kemudian akan dilakukan Proses Segmentasi Citra dengan Metode Otsu (jika TIDAK akan kembali ke proses Input Citra, jika YA akan lanjut ke proses selanjutnya) dengan melakukan langkah-langkah (Mencari nilai histogram and probability, kemudian mencari nilai bobot pada kedua kelas, selanjutnya mencari nilai rerata pada kedua kelas, kemudian mencari nilai rerata total, dan mencari nilai betwen class variance). Setelah itu kita akan mendapatkan citra hasil dari proses Segmentasi Citra dengan Menggunakan Metode Otsu. Langkah terakhir jika kita ingin menginput citra yang baru lakukan kembali proses input citra, jika ingin mengakhiri proses Segmentasi Citra dengan Metode Otsu maka End.

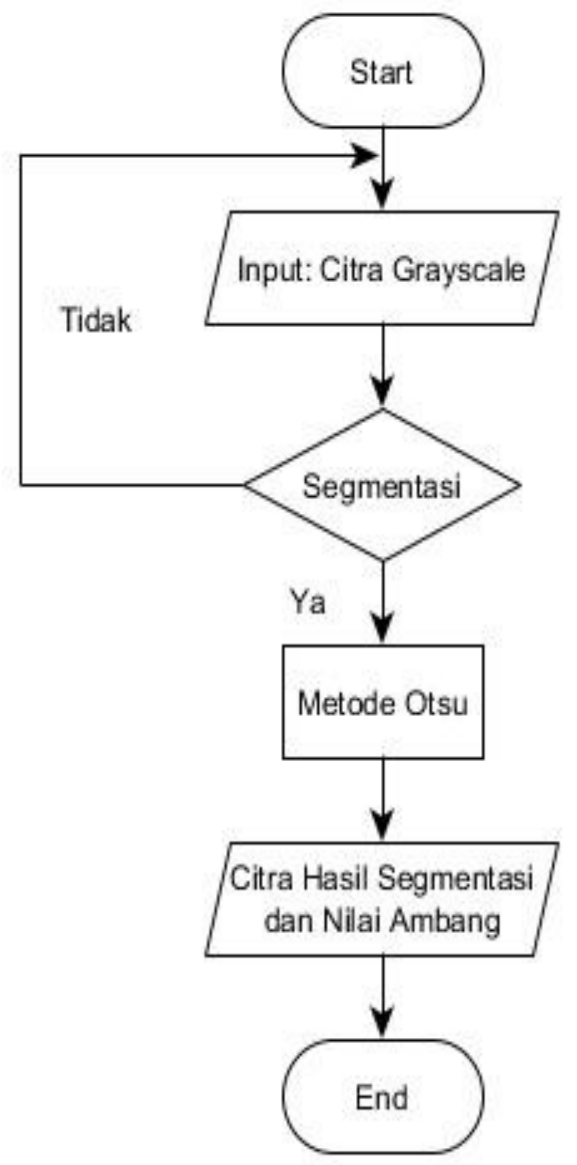

Gambar 3. Flowchart sistem

Gambar 3 merupakan flowchart sistem segmentasi citra naskah arab menggunakan metode Otsu dan menampilkan langkah-langkah yang harus ditempuh untuk menjalankan sistem segmentasi citra naskah arab dengan menggunakan metode Otsu. 


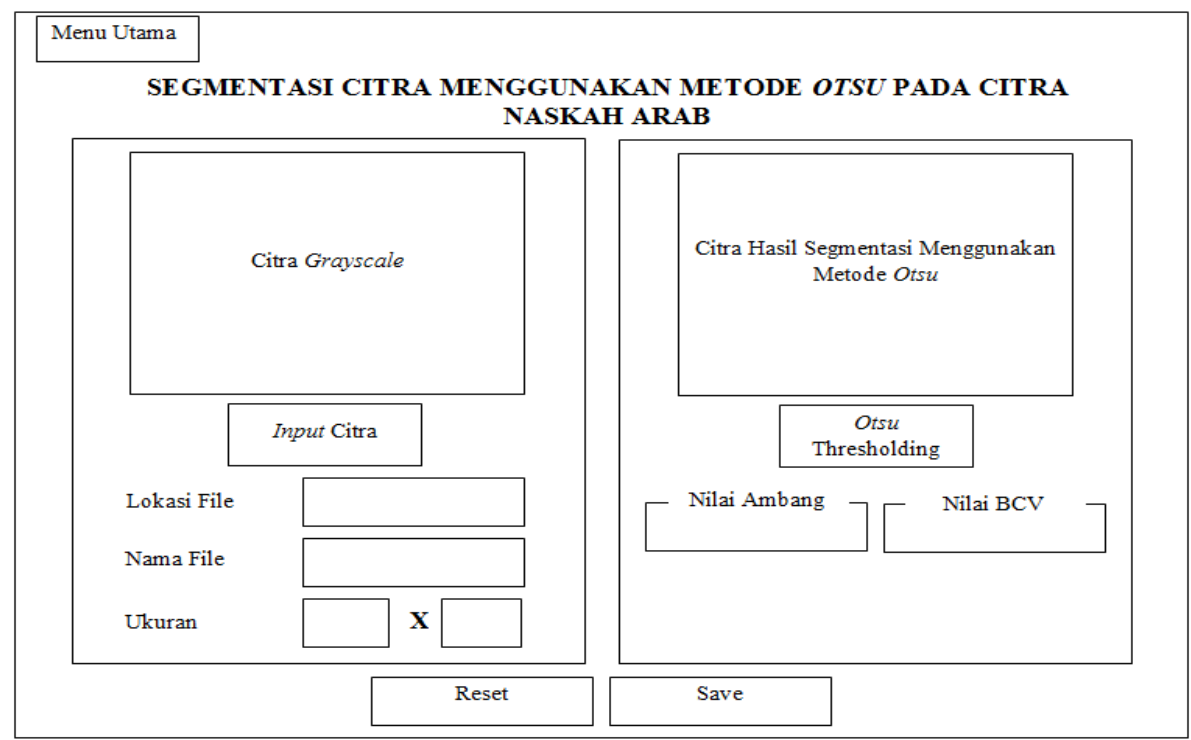

Gambar 4. Tampilan form proses segmentasi citra dengan mengimplementasikan metode Otsu

Gambar 4 merupakan tampilan form proses segmentasi citra dengan mengimplementasikan metode Otsu sebagai antar muka yang bertujuan untuk memudahkan user dalam menggunakan sistem tersebut.

\section{HASIL DAN ANALISA}

\subsection{Analisis Data}

Untuk pengimplementasian metode Otsu dalam proses segmentasi citra naskah arab, sampel citra yang digunakan merupakan citra 8x8 pixel dan berjenis grayscale.

Tabel 1. Sampel citra $8 \times 8$

\begin{tabular}{|c|c|c|c|c|c|c|c|}
\hline 182 & 196 & 193 & 189 & 193 & 189 & 193 & 195 \\
\hline 191 & 186 & 182 & 188 & 99 & 191 & 195 & 194 \\
\hline 193 & 188 & 189 & 104 & 188 & 183 & 179 & 184 \\
\hline 188 & 184 & 56 & 187 & 88 & 68 & 172 & 183 \\
\hline 188 & 179 & 144 & 175 & 65 & 130 & 161 & 188 \\
\hline 177 & 49 & 167 & 149 & 156 & 157 & 152 & 170 \\
\hline 164 & 82 & 150 & 126 & 158 & 147 & 104 & 173 \\
\hline 153 & 155 & 153 & 160 & 175 & 170 & 181 & 197 \\
\hline
\end{tabular}

Tabel 1 merupakan citra naskah arab yang digunakan sebagai sample dan telah dikompresikan kedalam bentuk tabel pixel.

\subsection{Hasil Analisis}

Berikut akan dilakukan proses segmentasi citra naskah arab berjenis grayscale 8 x 8 pixel dengan mengimplementasikan metode Otsu. 


\subsubsection{Input Citra Grayscale}

Citra naskah arab berjenis grayscale dengan ukuran citra 8x8 pixel dan berformat Bitmap Picture (BMP) akan digunakan sebagai sample.

\subsubsection{Proses Segmentasi dengan Metode Otsu}

Dibawah adalah alur kerja proses segmentasi dengan mengimplementasikan metode Otsu pada citra naskah arab.

\section{Histogram and Probability}

Objek dan latar belakang dapat dipisahkan dan dapat diketahui sebaran tingkat keabuannya dengan memanfaatkan suatu sistem merupakan defenisi histogram [12]. Informasi mengenai sebaran tingkat keabuan sebuah citra dapat dihitung menggunakan rumus dibawah:

$$
P(i)=\frac{n_{i}}{N}
$$

Keterangan:

$n i=$ jumlah pixel berintansitas $i$

$N=$ Jumlah semua pixel dalam citra

Tabel 2. Citra naskah $\operatorname{arab} 8 \times 8$

\begin{tabular}{|c|c|c|c|c|c|c|c|}
\hline 182 & 196 & 193 & 189 & 193 & 189 & 193 & 195 \\
\hline 191 & 186 & 182 & 188 & 99 & 191 & 195 & 194 \\
\hline 193 & 188 & 189 & 104 & 188 & 183 & 179 & 184 \\
\hline 188 & 184 & 56 & 187 & 88 & 68 & 172 & 183 \\
\hline 188 & 179 & 144 & 175 & 65 & 130 & 161 & 188 \\
\hline 177 & 49 & 167 & 149 & 156 & 157 & 152 & 170 \\
\hline 164 & 82 & 150 & 126 & 158 & 147 & 104 & 173 \\
\hline 153 & 155 & 153 & 160 & 175 & 170 & 181 & 197 \\
\hline
\end{tabular}

Tabel 2 merupakan tabel pixel citra naskah arab 8 × 8 yang digunakan sebagai sample untuk menjalankan langkah-langkah yang harus ditempuh dalam melakukan proses segmentasi citra naskah arab dengan menggunakan metode $\mathrm{Otsu}$. tersebut.

Dalam menentukan histogram dari citra naskah arab yang akan di uji maka urutkanlah nilai pixel dari citra 
$\mathrm{N}=64$

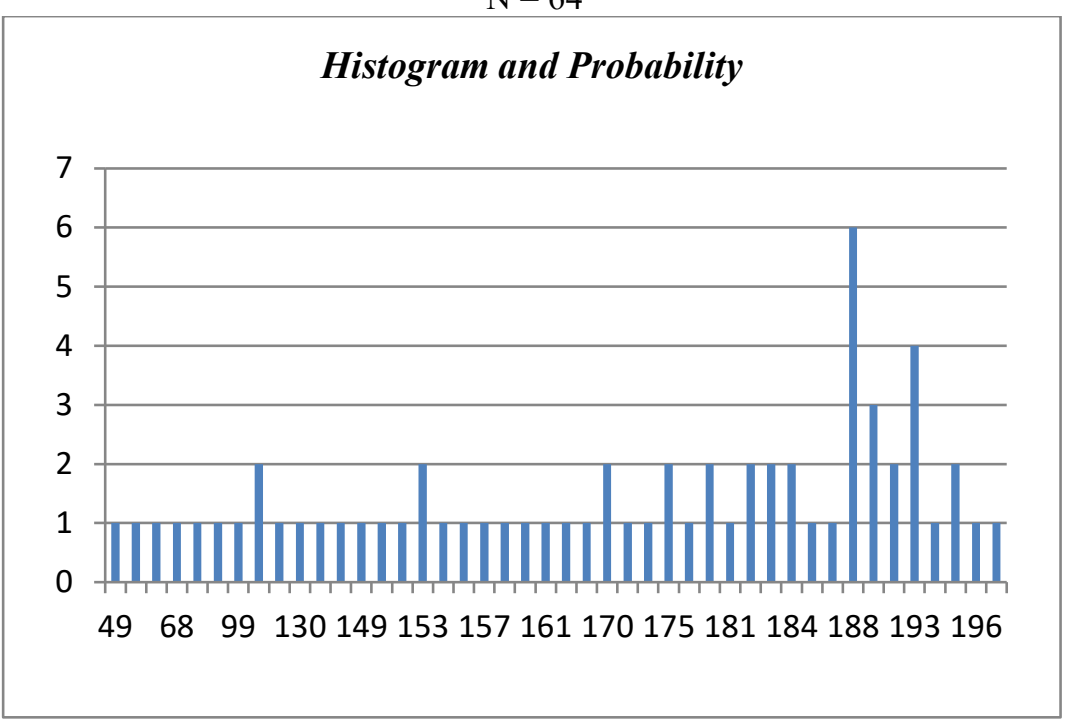

Gambar 5. Histogram citra $8 \times 8$ pixel

Gambar 5 merupakan gambar histogram citra naskah arab yang akan di uji dan telah diurutkan nilai pixelnya mulai dari nilai pixel yang terkecil hingga nilai pixel yang terbesar.

Menentukan nilai $\mathrm{T}_{\text {awal }}$ yaitu nilai rata-rata intensitas citra:

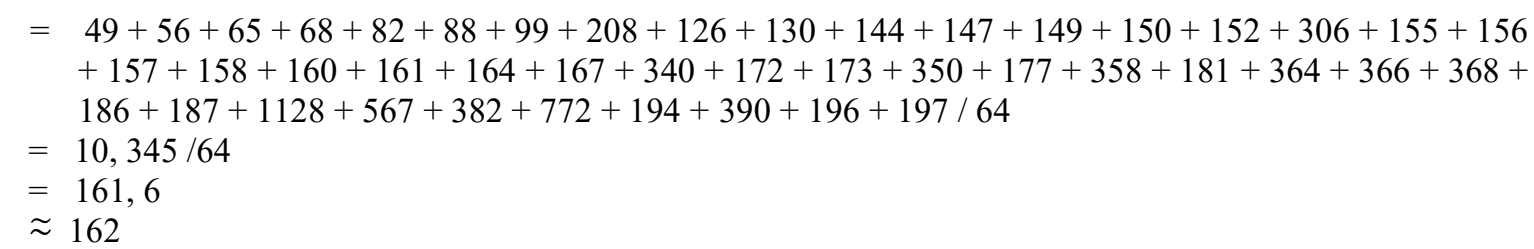

Mencari nilai $\mathrm{T}_{1}$ :

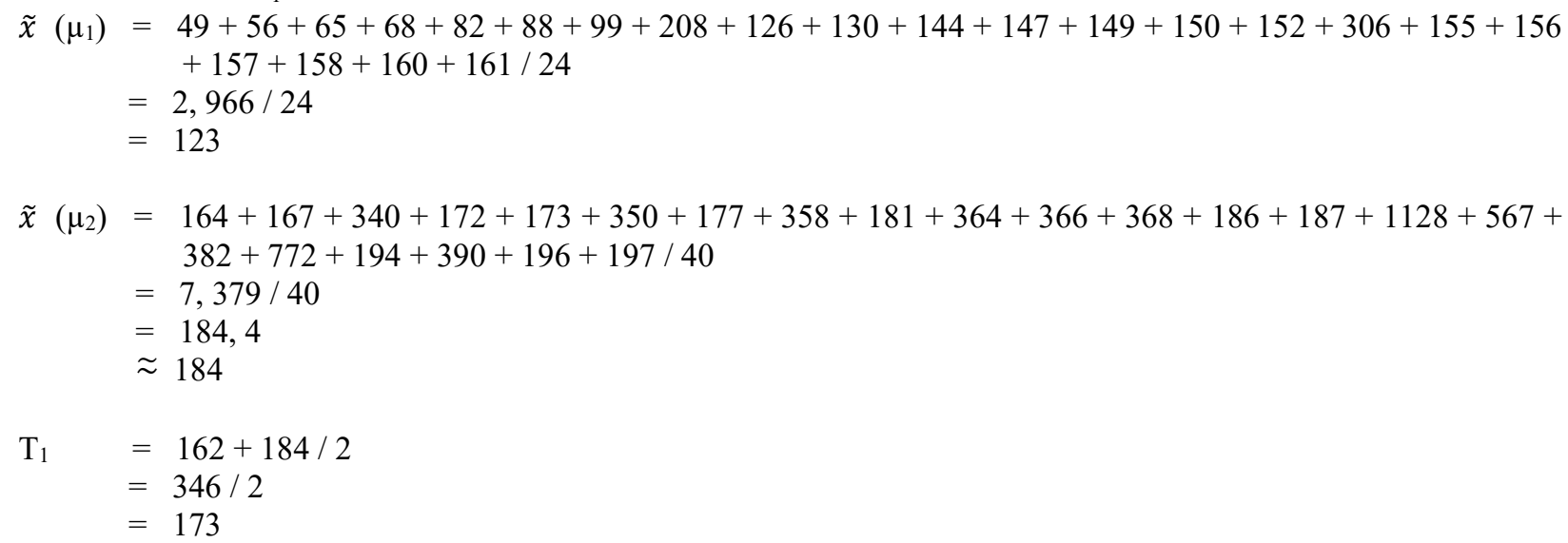

Mencari nilai $\mathrm{T}_{2}$ :

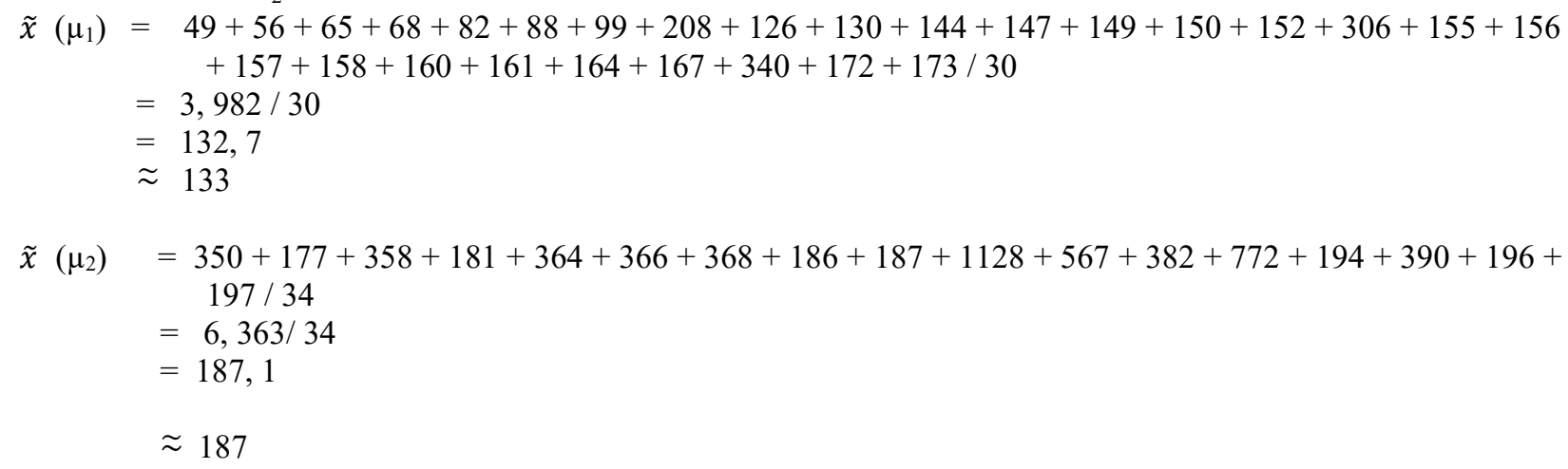




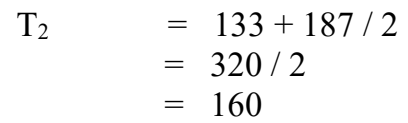

Mencari nilai $\mathrm{T}_{3}$ :

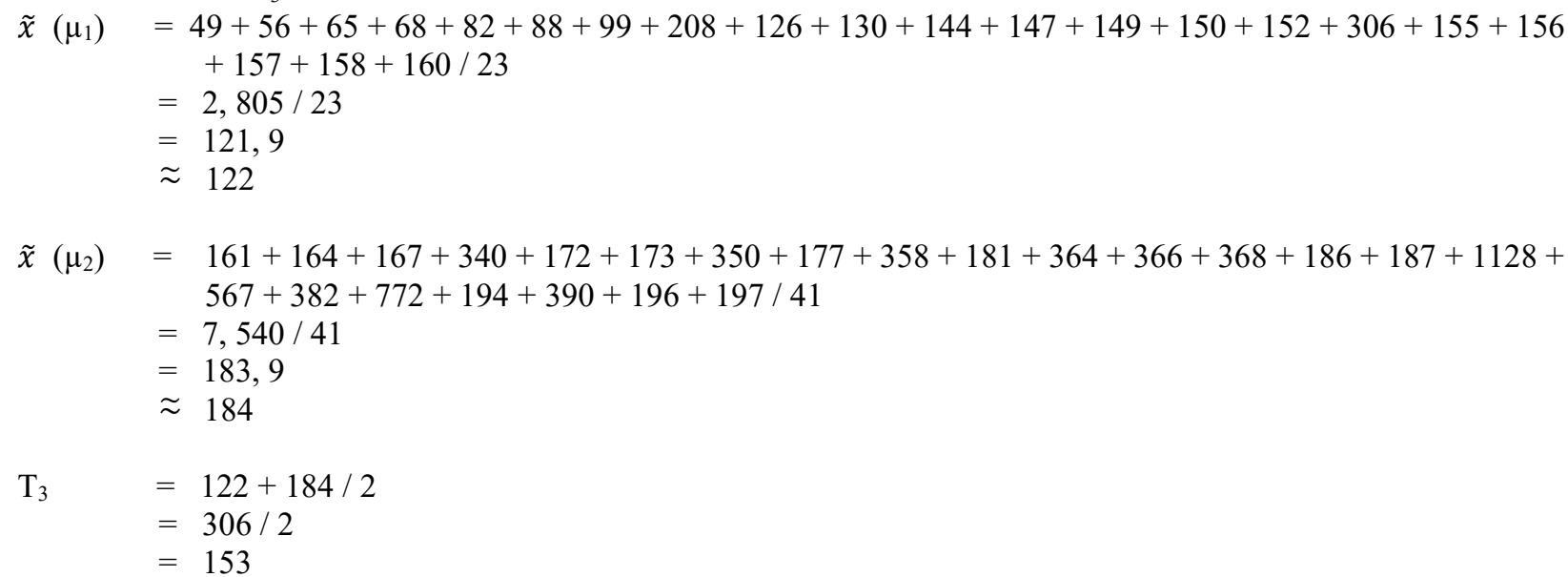

Mencari nilai $\mathrm{T}_{4}$ :

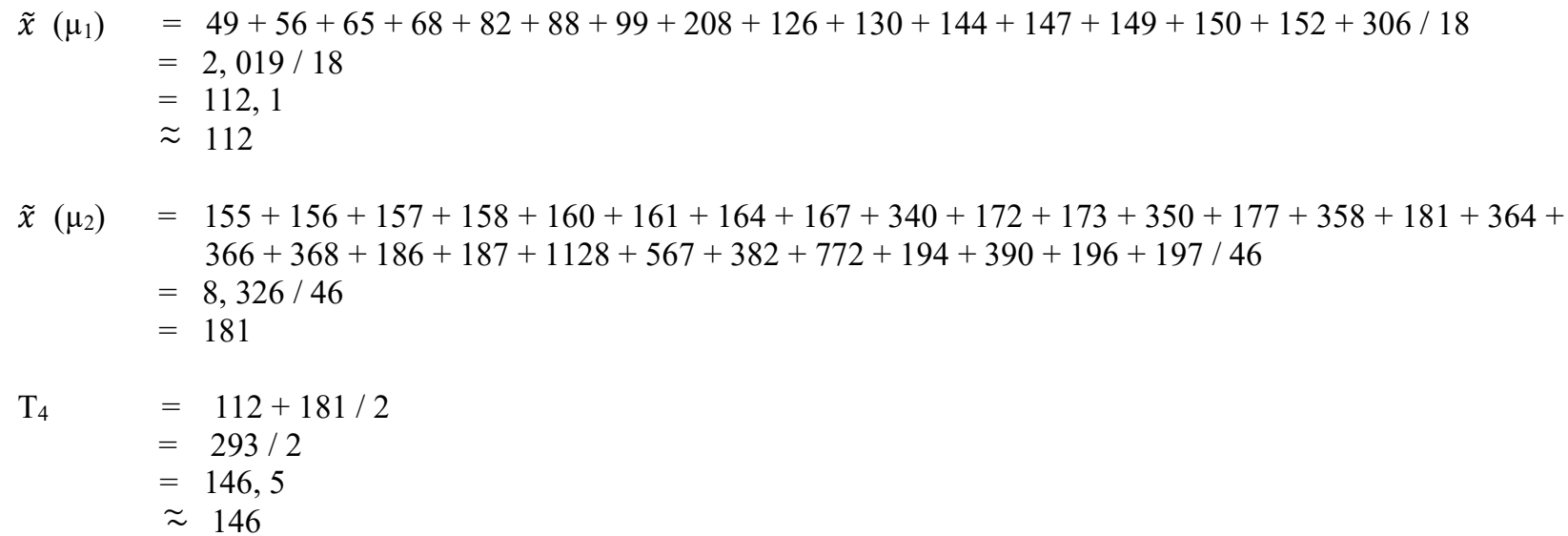

Mencari nilai $\mathrm{T}_{5}$ :

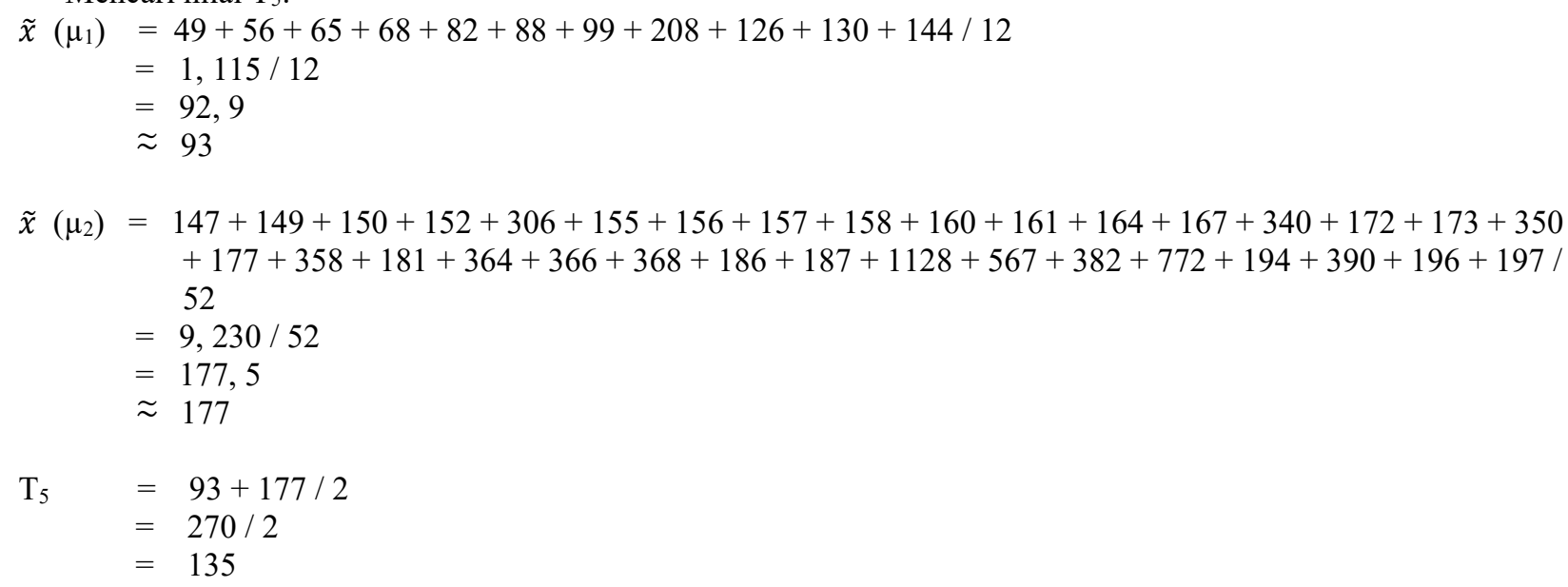

Mencari nilai $\mathrm{T}_{6}$ :

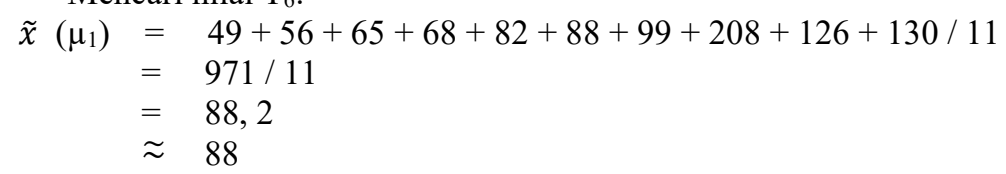




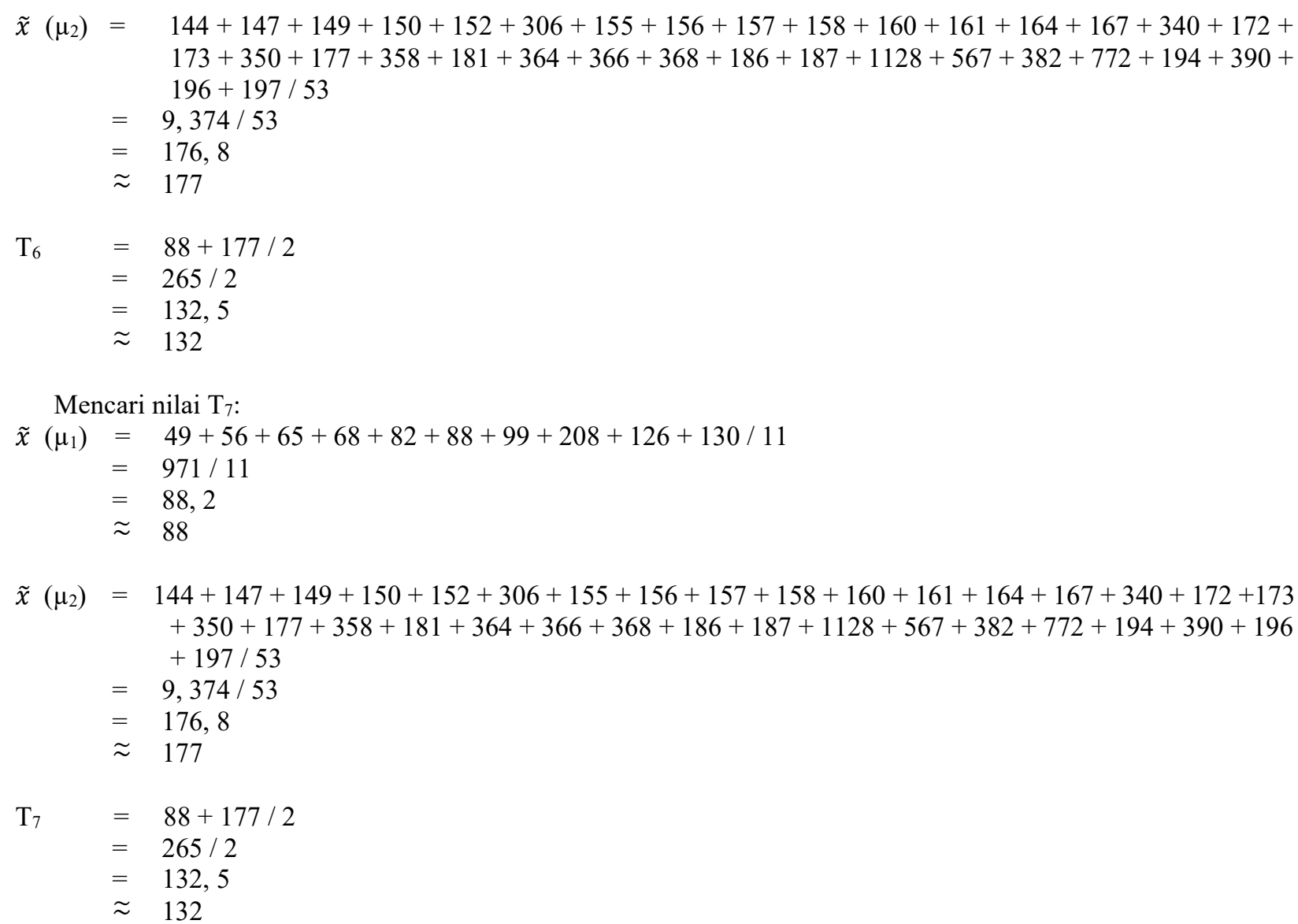

Setelah dilakukan perhitungan sebanyak 7 kali, nilai $\mu_{1}$ dan $\mu_{2}$ tidak berubah lagi. Maka dari itu perhitungan nilai berhenti sampai di titik 132. Karena pada histogram tidak ada titik 132, maka nilai ambang ditentukan pada titik terdekat dari 132 yaitu 130 .

2. Nilai bobot terhadap kedua kelas:

$$
\begin{aligned}
w_{1}(\mathrm{t})= & \sum_{i=1}^{t} \mathrm{P}(i) \\
= & 0,015625+0,015625+0,015625+0,015625+0,015625+0,015625+0,015625+0,03125+ \\
& 0,015625+0,015625 \\
= & 0,171875 \\
w_{2}(\mathrm{t})= & \sum_{i=t+1}^{\mathrm{L}} \mathrm{P}(i) \\
= & 0,015625+0,015625+0,015625+0,015625+0,015625+0,03125+0,015625+0,015625+ \\
& 0,015625+0,015625+0,015625+0,015625+0,015625+0,015625+0,03125+0,015625+ \\
& 0,015625+0,03125+0,015625+0,03125+0,015625+0,03125+0,03125+0,03125+0 \\
& 015625+0,015625+0,09375+0,046875+0,03125+0,0625+0,015625+0,03125+0 \\
& 015625+0,015625 \\
= & 0,828125
\end{aligned}
$$

Keterangan:

$\mathrm{L}=$ Jumlah aras keabuan

3. Rerata kedua kelas:

$$
\begin{aligned}
m_{1}(t)= & \sum_{i=1}^{t} i . \mathrm{P}(\mathrm{i}) / w_{1}(t) \\
= & (49 \times 0,015625)+(56+0,015625)+(65 \times 0,015625)+(68 \times 0,015625)+(82 \times 0,015625)+(88 \\
& \quad \times 0,015625)+(99 \times 0,015625)+(104 \times 0,03125)+(126 \times 0,015625)+(130 \times 0,015625) / 0, \\
& 171875
\end{aligned}
$$




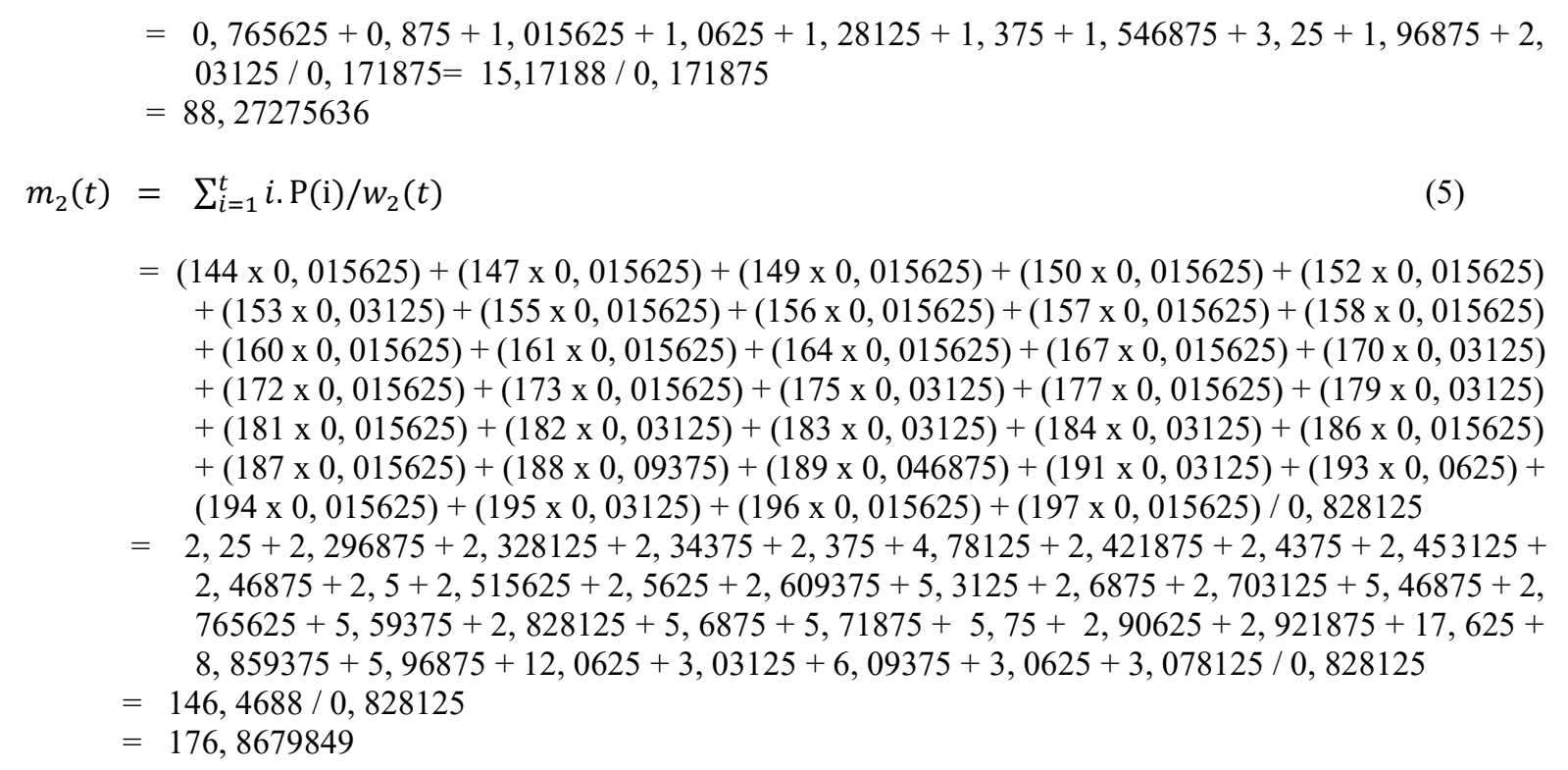

4. Rerata total dinyatakan sebagai berikut:

$$
\begin{aligned}
m_{\mathrm{T}}= & \sum_{i=1}^{N} i . \mathrm{P}(i) \\
= & (49 \times 0,015625)+(56+0,015625)+(65 \times 0,015625)+(68 \times 0,015625)+(82 \times 0,015625)+(88 \times \\
& 0,015625)+(99 \times 0,015625)+(104 \times 0,03125)+(126 \times 0,015625)+(130 \times 0,015625)+(144 \times \\
& 0,015625)+(147 \times 0,015625)+(149 \times 0,015625)+(150 \times 0,015625)+(152 \times 0,015625)+(153 \\
& \times 0,03125)+(155 \times 0,015625)+(156 \times 0,015625)+(157 \times 0,015625)+(158 \times 0,015625)+ \\
& (160 \times 0,015625)+(161 \times 0,015625)+(164 \times 0,015625)+(167 \times 0,015625)+(170 \times 0,03125) \\
& +(172 \times 0,015625)+(173 \times 0,015625)+(175 \times 0,03125)+(177 \times 0,015625)+(179 \times 0,03125) \\
& +(181 \times 0,015625)+(182 \times 0,03125)+(183 \times 0,03125)+(184 \times 0,03125)+(186 \times 0,015625) \\
& +(187 \times 0,015625)+(188 \times 0,09375)+(189 \times 0,046875)+(191 \times 0,03125)+(193 \times 0,0625)+ \\
& (194 \times 0,015625)+(195 \times 0,03125)+(196 \times 0,015625)+(197 \times 0,015625) \\
= & 0,765625+0,875+1,015625+1,0625+1,28125+1,375+1,546875+3,25+1,96875+2, \\
& 03125+2,25+2,296875+2,328125+2,34375+2,375+4,78125+2,421875+2,4375+2, \\
& 453125+2,46875+2,5+2,515625+2,5625+2,609375+5,3125+2,6875+2,703125+5, \\
& 46875+2,765625+5,59375+2,828125+5,6875+5,71875+5,75+2,90625+2,921875+ \\
& 17,625+8,859375+5,96875+12,0625+3,03125+6,09375+3,0625+3,078125 \\
= & 161,6406
\end{aligned}
$$

5. Between Class Variance dihitung melalui:

$$
\begin{aligned}
\sigma_{B}^{2}(t) & =w_{1} \cdot\left[m_{1}(t)-m_{\mathrm{T}}\right]^{2}+w_{2} \cdot\left[m_{2}(t)-m_{\mathrm{T}}\right]^{2} \\
& =0,171875[88,27275636-161,6406]^{2}+0,828125[176,8679849-161,6406]^{2} \\
& =0,171875[-73,3678436]^{2}+0,828125[15,2273849]^{2} \\
& =[0,171875 \times 5,382.840475]+[0,828125 \times 231,8732509] \\
& =925,1757066+192,0200359 \\
& =1,117.195742
\end{aligned}
$$

Hasil dari sebuah proses yang telah dilakukan sebelumnya yaitu dapat dilihat bahwa setelah di segmentasi citra naskah arab dengan mengimplementasikan metode Otsu mengalami perubahan nilai intensitas warna dengan memperoleh nilai ambang 130 dan nilai Between Class Variance 1, 117. 195742.

\section{Thresholding}

Sebuah metode yang dapat dipakai untuk melakukan proses segmentasi objek dalam sebuah gambar merupakan metode Threshold (Pengambangan) [13]. Dari proses pengambangan dapat dihasilkan sebuah citra biner. Nilai pixel 0 didapatkan jika pixel yang mempunyai derajat keabuan lebih tinggi nilainya dibandingkan dengan nilai ambang $(\mathrm{T})$, dan jika nilai pixel yang mempunyai derajat keabuan lebih rendah nilainya dibandingkan dengan nilai ambang (T) akan mendapatkan nilai pixel 1 [14]. 


$$
T(x, y)=\left\{\begin{array}{l}
1 \text { jikaf }(x, y) \leq T(x, y) \\
0 \text { jikaf }(x, y) \geq T(x, y)
\end{array}\right\}
$$

Tabel 3. Nilai pixel citra asli

\begin{tabular}{|l|l|l|l|l|l|l|l|}
\hline 182 & 196 & 193 & 189 & 193 & 189 & 193 & 195 \\
\hline 191 & 186 & 182 & 188 & 99 & 191 & 195 & 194 \\
\hline 193 & 188 & 189 & 104 & 188 & 183 & 179 & 184 \\
\hline 188 & 184 & 56 & 187 & 88 & 68 & 172 & 183 \\
\hline 188 & 179 & 144 & 175 & 65 & 130 & 161 & 188 \\
\hline 177 & 49 & 167 & 149 & 156 & 157 & 152 & 170 \\
\hline 164 & 82 & 150 & 126 & 158 & 147 & 104 & 173 \\
\hline 153 & 155 & 153 & 160 & 175 & 170 & 181 & 197 \\
\cline { 3 - 10 } & 5
\end{tabular}

Tabel 4. Nilai pixel hasil segmentasi citra dengan mengimplementasikan metode Otsu

\begin{tabular}{|c|c|c|c|c|c|c|c|}
\hline 0 & 0 & 0 & 0 & 0 & 0 & 0 & 0 \\
\hline 0 & 0 & 0 & 0 & 1 & 0 & 0 & 0 \\
\hline 0 & 0 & 0 & 1 & 0 & 0 & 0 & 0 \\
\hline 0 & 0 & 1 & 0 & 1 & 1 & 0 & 0 \\
\hline 0 & 0 & 0 & 0 & 1 & 0 & 0 & 0 \\
\hline 0 & 1 & 0 & 0 & 0 & 0 & 0 & 0 \\
\hline 0 & 1 & 0 & 1 & 0 & 0 & 1 & 0 \\
\hline 0 & 0 & 0 & 0 & 0 & 0 & 0 & 0 \\
\hline
\end{tabular}

Tabel 3 merupakan tabel pixel citra naskah arab sebelum disegmentasi dengan menggunakan metode Otsu dan setelah dilakukan pengujian secara otomatis didapatkan nilai ambang (T) 130, tabel 4 merupakan tabel pixel hasil dari citra naskah arab yang telah disegmentasi menggunakan metode Otsu.

\subsection{Implementasi}

Sistem segmentasi citra dengan metode Otsu diimplementasikan menggunakan tool Matlab. Matlab merupakan Software dengan bahasa pemrograman tingkat tinggi, memiliki kemampuan grafis yang baik, dan dipakai untuk menganalisis data-data, memvisualisasi tool dan prototyping matematis dengan dukungan operasi matrik [15]. Gambar 6 merupakan bentuk dari form awal dari sistem yang sudah dibuat. 


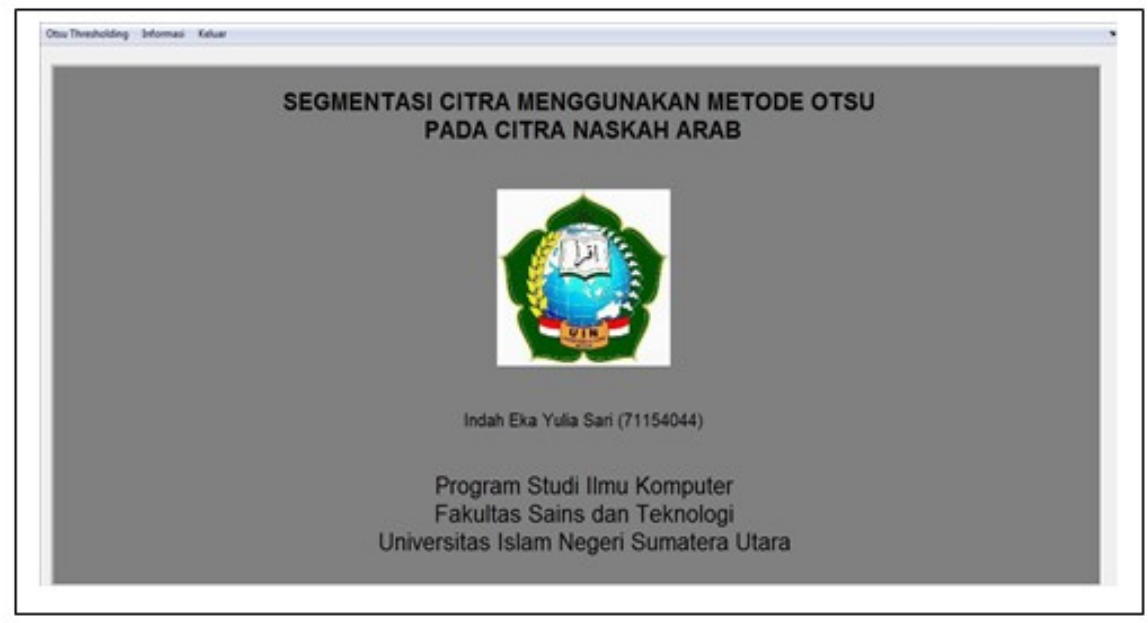

Gambar 6. Form awal

Gambar 7 merupakan bentuk form segmentasi citra dengan mengimplementasikan metode Otsu yang terdapat di sistem yang sudah dibuat. Pada gambar dibawah di tampilkan hasil dari pengujian yang sudah dilakukan pada salah satu sampel.

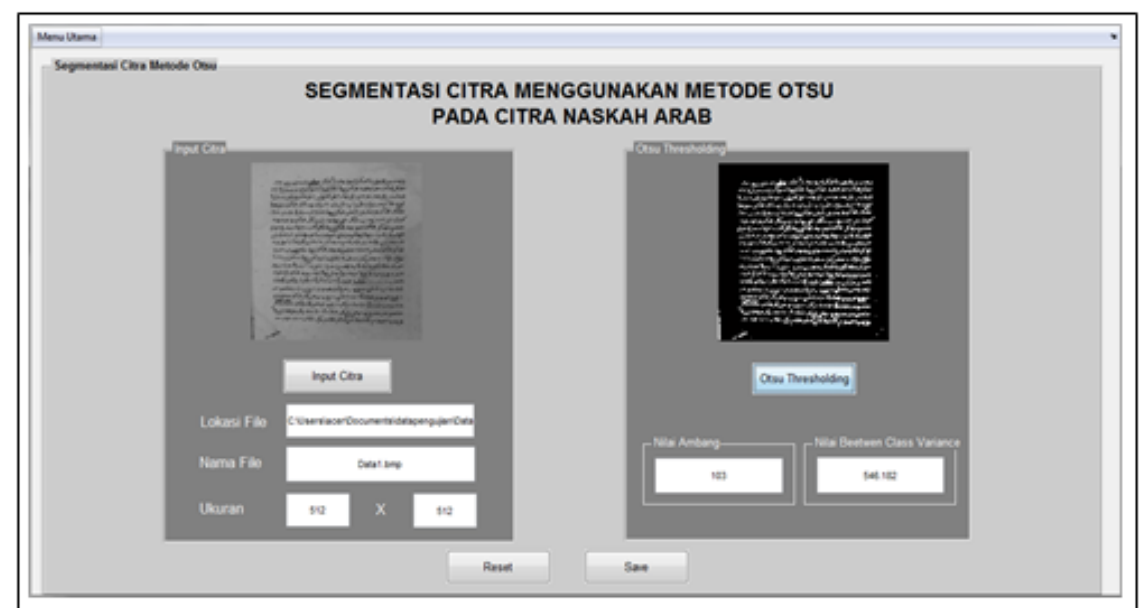

Gambar 7. Form segmentasi citra naskah arab dengan mengimplementasikan metode Otsu

\section{KESIMPULAN}

Dari penelitian yang telah dilakukan maka diperoleh kesimpulan bahwa kecerahan pada citra naskah arab dipengaruhi oleh pencahayaan yang baik sehingga hasilnya menjadi maksimal, mengimplementasikan metode Otsu telah terbukti bisa mempersingkat waktu dalam melakukan proses segmentasi di dalam sebuah komputer dan berdasarkan citra yang dimasukkan bisa menghasilkan nilai ambang maksimal dengan cara otomatis, pada metode Otsu nilai ambang yang optimal dapat dihasilkan dengan cara memaksimumkan nilai Between Class Variance dan hasilnya begitu baik karena tulisan yang ada pada naskah arab terlihat lebih jelas sehingga informasi di dalamnya juga tidak berkurang.

Untuk pengembangan selanjutnya dari penelitian yang sudah pernah dilakukan tentang sistem segmentasi dengan menerapkan metode Otsu pada citra naskah arab yaitu untuk mengurangi bercak (noise) yang ada pada naskah arab sebaiknya sistem ini dilengkapi dengan proses filtering, metode yang digunakan saat ini juga dapat dibandingkan dengan metode multilevel thresholding, karena citra terdiri dari beberapa jenis untuk kedepannya dapat dikembangkan agar sistem ini dapat mengenali berbagai jenis citra yang ada.

\section{UCAPAN TERIMA KASIH}

Penulis mengucapkan terima kasih kepada para pimpinan Program Studi Ilmu Komputer, Fakultas Sains dan Teknologi, Universitas Islam Negeri Sumatera Utara Medan yang telah banyak memberikan dorongan semangat, moril dan dorongan material sehingga penelitian ini dapat diselesaikan dengan baik. 


\section{REFERENSI}

[1] O. Fathurahman, Filologi dan Islam Indonesia. Jakarta: Puslitbang Lektur Keagamaan, Badan Litbang dan Diklat, Kementerian Agama, 2010, 2010.

[2] E. Roza, "Aksara Arab-Melayu di Nusantara dan Sumbangsihnya dalam Pengembangan Khazanah Intelektual," Tsaqafah, vol. 13, no. 1, pp. 180-181, 2017.

[3] P. Hidayatullah, Pengolahan Citra Digital Teori dan Aplikasi Nyata. Bandung, 2017.

[4] Sriani, Triase, and Khairuna, "Pendekomposisian Citra Digital Dengan Algoritma DWT," Jurnal Ilmu Komputer dan Informatika, vol. 1, no. 1, pp. 35-39, 2017.

[5] Sriani, A. Ikhwan, and Yusnidah, “Aplikasi Metode Transformasi Wavelet Diskrit,” Jurnal Sains Manajemen Informatika dan Komputer, vol. 16, no. 1, 2017.

[6] T. S. Pulung Nurtantio Andono and Muljono, Pengolahan Citra Digital. Yogyakarta, 2017.

[7] V. S. O. D. N. W. T Sutoyo Edi Mulyanto, Teori Pengolahan Citra Digital. Yogyakarta: Penerbit Andi, 2009.

[8] D. Putra, Pengolahan Citra digital. Yogyakarta: Andi, 2010.

[9] A. S. Abdul Kadir, Teori dan Aplikasi Pengolahan Citra. Yogyakarta, 2013.

[10] S. E, Algoritma: Teknik Penyelesaian Permasalahan untuk Komputasi. Yogyakarta: Graha Ilmu, 2004.

[11] Jogiyanto, Analisis dan Desain Sistem Informasi. Yogyakarta: Andi, 2007.

[12] M. H. Purnomo and A. Muntasa, Konsep Pengolahan Citra Digital dan Ekstrasi Fitur. Yogyakarta: Graha Ilmu, 2010.

[13] L. Anggraini, "Segmentasi Citra dengan Metode Threshold pada Citra Digital Tanaman,” in Seminar Nasional Riset Ilmu Komputer, 2018, pp. 144-145.

[14] Sriani and M. Ikhsan, "Implementasi Kompresi Citra Digital Menggunakan Algoritma Wavelet," Konferensi Nasional Pengembangan Teknologi Informasi dan Komunikasi, pp. 258-266, 2016.

[15] W. Komputer, Ragam Aplikasi Pengolahan Image dengan Matlab. Jakarta: PT. Elex Media Komputindo, 2013. 